\title{
Development of Potential Aerobic Rice Cultivar through Participatory Varietal Selection Employing Aerobic Response Index
}

\author{
A.K. Mall ${ }^{*}$, S.K. Pradhan and O.N. Singh \\ Central Rice Research Institute, Cuttack-753 006, Orissa, India \\ *Corresponding author
}

\section{A B S T R A C T}

Twelve rice genotypes with three checks were evaluated under aerobic conditions using a randomized complete block design with three replications. GE interaction was analyzed using linear regression techniques. There was considerable variation for grain yield among both genotypes and environments. The regression coefficient for genotype CR 2624 was almost unity and had one of the lowest deviations from regressions with high coefficient of

\section{Keywords}

Aerobic rice, Stability, ARI, Relative Yield, PVS.

\section{Article Info}

Accepted:

27 June 2017

Available Online:

10 August 2017 determination, confirming its stability. In contrast, genotypes IR 78875-53-2-2-2 and IR 78878-53-2-2-4 showed regression coefficients less than 1, indicating insensitivity to environmental changes for grain yield. Low and consistent ARI is confirming their stability. The ARI is a yield stability parameter which is based on grain yield reduction under stress. Genotypic variation in ARI was consistent for tested genotypes among all the farmers' field and genotypic mean ARI ranged from 0.71 to 1.65 . The mean values of ARI for grain yield (GY) were less than 1, indicated the relative tolerance of this character in this study. Grain yield reduction ranged from 12.83 (Annada) to 29.70 per cent (Lalat) in aerobic rice w.r.t. irrigated condition. The significant and positive correlations were obtained between ARI and GY under irrigated condition, whereas negative association in aerobic condition. Three genotypes namely, Anjali, Lalat and IR 79906-B-5-3-3 were identified as inconsistent ARI performers over the farmers' field. The inconsistence of the estimates in ARI across farmers' field reflects the nature of the large G x E interactions observed for grain yield under aerobic condition. Simultaneously, CR 2624, IR 78875-532-2-2 and IR 78878-53-2-2-4 may be suggested for target area during dry season. Involvement of the client farmers in the breeding and selection process will be very much helpful in finding new varieties, which combine higher grain yield with the necessary characters for the farmers with water scarcity in irrigated/ lowland rice.

\section{Introduction}

Food security in India is challenged by increasing food demand and threatened by "physical water scarcity" in present and "economic water scarcity" in future. Rice consumes more than 50 per cent of the water used for irrigation in Asia (Barker et al., 1999). Several strategies are being pursued to reduce rice water requirements, such as saturated soil culture (Borrel et al., 1997), alternate wetting and drying (Li 2001, Tabbal et al., 2002), ground cover systems (Lin Shan et al., 2002), system of rice intensification (SRI, Stoop et al., 2002), aerobic rice (Bouman et al., 2002), and raised beds (Singh et al., 2002). It is reported that SRI and AWD systems have high water productivity with some amount of saving (approx. 20 per cent) without any compromise on productivity. However, water requirement of these production systems is also very high as land 
preparation consists of soaking, followed by wet ploughing or puddling of saturated soil except Aerobic system.

To safeguard food security and preserve precious water resources, ways must be explored to grow rice using less water, hence shifting gradually from traditional rice production system to grow rice aerobically, can mitigate occurrence of water related problems. In, India, upland rice is already grown aerobically with minimal inputs but mostly as a low yielding subsistence crop to give stable yield under adverse conditions of the uplands. Alternatively, high yielding lowland rice varieties grown under aerobic soil conditions, but with supplemental irrigation, have been shown to save water, but at a severe yield penalty. Achieving high yields under irrigated but aerobic soil conditions requires new varieties of "aerobic rice" that combine the drought tolerant characteristics of upland varieties with the high yielding characteristics of lowland varieties. Yield penalty and yield stability of aerobic rice have to be considered before promoting this technology in subtropical India in general and coastal Orissa in particular.

In view of above discussion, a multi-location on-farm evaluation of promising aerobic rice genotypes was carried out under farmers' participatory mode in the four project adopted villages in Cuttack district under "Asian Development Bank (ADB) funded collaborative research programme between IRRI, Philippines and Indian Council of Agricultural Research/Central Rice Research Institute, Cuttack.

\section{Materials and Methods}

On the basis of performance in advanced yield trials (AYT) over the years under aerobic and irrigated conditions, twelve selected promising genotypes including three checks were evaluated at four farmer's field viz., Kochila Nuagaon $\left(\mathrm{E}_{1}\right)$ : The village is partially irrigated from a perennial stream (Damanijhar) from the hills and a watershed (Mahichua bandh); Brahmanabasta $\left(\mathrm{E}_{2}\right)$ : The village is partially irrigated from a lift irrigation point (LIP) from Mahanadi river (3 $\mathrm{km}$ away) and also from the local Nala (drainage channel) which passes near the village; Samian $\left(E_{3}\right)$ : the village is partially irrigated from a Minor Irrigation project called Kalakala Minor Irrigation Project (popularly known as Gaapal Bandh) and Ratanpur $\left(\mathrm{E}_{4}\right)$ : The village is largely irrigated from government canal under participatory varietal selection trials to identify suitable genotypes under aerobic condition for target environments during dry season, 2011.

The experiments were conducted in Randomized Complete Block Design with three replications under two water regimes: (a) aerobic condition under non flooded and non-puddled condition at on-farm and (b) irrigated condition at on-station. Rice varieties under aerobic condition were directly sown at 2-3 cm soil depth in dry and pulverized soil by hand plough with the seed rate of $60 \mathrm{Kg} \mathrm{ha}^{-1}$ to maintain 3-4 seeds hill ${ }^{-1}$. Twenty one days old seedlings were transplanted under irrigated condition in same plot size used for aerobic condition. Peizometers $(200 \mathrm{~cm}$ length and $5 \mathrm{~cm}$ diameter PVC pipe) were installed in all the treatments to monitor the ground water fluctuation to guide the timing of irrigation. Experimental plots were maintained at near saturation and re-watered only when soil moisture reached below $15 \mathrm{~cm}$ and under irrigated condition was designed to maintain assured soil moisture by keeping $5 \mathrm{~cm}$ pounded water. Standard cultural procedures were adopted and need based plant protection was given. Phosphorus (40 kg ha $\left.{ }^{-1} \mathrm{P}_{2} \mathrm{O}_{5}\right)$ and potassium $\left(40 \mathrm{~kg} \mathrm{ha}^{-1} \mathrm{~K}_{2} \mathrm{O}\right)$ were applied as recommended before sowing/planting in 
aerobic and transplanted conditions. Urea was used as source of $\mathrm{N}$ in three split doses. Preemergence herbicide Pretilachlor at $0.5 \mathrm{Kg}$ a.i. ha $^{-1}$ was applied at 3 DAS followed by hand weeding at 20 DAS and 45 DAS.

The data were analyzed by appropriate statistical analysis (Gomez and Gomez, 1984) using CropStat 7.2 (2009) programme. Aerobic response index (ARI) was calculated on the basis of mean data of on-farm under aerobic and on-station under irrigated experiments, following Fischer and Maurer (1978) used for drought susceptibility index. The data were analyzed by appropriate statistical analysis (Gomez and Gomez, 1984) using Crop Stat 7.2 (IRRI, 2009) programme. The stability analysis computed following Singh and Chaudhury (1985).

\section{Results and Discussion}

Grain yield under aerobic condition is a function of yield potential and aerobic response. Therefore, the use of the aerobic response index (ARI) can help to distinguish suitable variety for aerobic adaptation from the angle of phenology and yield potential. Four genotypes viz., IR 78875-131-B-1-4, IR 78875-53-2-2-2, IR 78878-53-2-2-4 and CR 2624 were recorded highest grain yield over the grand mean under aerobic conditions at four farmers filed.

\section{Aerobic response index (ARI)}

Grain yield under aerobic condition is a function of yield potential and aerobic response. Therefore, the use of the aerobic response index (ARI) can help to distinguish suitable variety for aerobic adaptation from the angle of phenology and yield potential.

The ARI is a yield stability parameter which is based on grain yield reduction under stress. Grain yield reduction ranged from 12.83
(Annada) to 29.70 per cent (Lalat) under aerobic condition. The mean values of ARI for grain yield (GY) were less than 1, indicated the relative tolerance of this character in this study. The significant and positive correlations were obtained between ARI and GY under irrigated condition $\left(r=0.333^{* *}, 0.551^{* *}, 0.465^{* *}\right.$ and $\left.0.424 * *\right)$, whereas negative association $(r=-0.720 * *$, $0.556^{* *},-0.506^{* *}$ and $\left.-0.464^{* *}\right)$ in aerobic condition on station.

This result is in agreement with Pantuwan et al., (2002) under reproductive stage drought stress. Desirable correlation between yield and ARI indicated that selection for ARI under aerobic condition would allow breeders to identify genotypes with high yield potential under aerobic condition for water limiting areas in tropics. All the genotypes under study recorded low ARI $(A R I<1)$ over the locations and among them, CR 2624, IR 78878-53-2-24 and IR 78875-53-2-2-2 were recorded lowest ARI for seed yield over the farmers field, thereby indicating that the genotypes were tolerant to water limiting conditions. Furthermore, only CR 2624 was yielded above $4 \mathrm{t} \mathrm{ha}^{-1}$ under both the conditions and lowest ARI performer over the locations.

\section{Relative yield under aerobic condition $\left(\mathbf{R} \mathbf{Y}_{\text {SS }}\right)$}

A stress tolerant genotype necessarily not has a high yield potential. The mean relative grain yields values under aerobic condition were 0.86 in $F_{1}, 0.87$ in $F_{2}, 0.89$ in $F_{3}$ and 0.86 in $\mathrm{F}_{4}$. The genotypes CR 2624 and IR 78878-532-2-4 were relatively high yielding (RY> mean RY) and check varieties, while rest of the genotypes in all the environments were relatively low yielding ( $\mathrm{RY}<$ mean $\mathrm{RY}$ ) in this study except IR 79906-B-192-2-1, IR 78875-131-B-1-4 and IR 78875-53-2-2-2. Similar finding was reported by Ahmad et al., (2003). 
Table.1 Genotypic mean performance under aerobic and irrigated conditions and their aerobic response index (ARI) for grain yield $\left(\mathrm{t} \mathrm{ha}^{-1}\right)$ at farmer's field

\begin{tabular}{|c|c|c|c|c|c|c|c|c|c|c|c|}
\hline \multirow[t]{2}{*}{ S. $\mathbf{N}$. } & \multirow[t]{2}{*}{ Genotypes } & \multicolumn{5}{|c|}{ ARI over the locations } & \multicolumn{5}{|c|}{ Relative Yield under Aerobic } \\
\hline & & $\mathbf{E}_{1}$ & $\mathbf{E}_{2}$ & $\mathbf{E}_{3}$ & $\mathbf{E}_{4}$ & Mean & $\mathbf{E}_{1}$ & $\mathbf{E}_{2}$ & $\mathbf{E}_{3}$ & $\mathbf{E}_{4}$ & Mean \\
\hline 1 & IR 78875-53-2-2-2 & 0.69 & 0.96 & 0.92 & 0.82 & 0.90 & 0.91 & 0.87 & 0.89 & 0.90 & 0.90 \\
\hline 2 & IR 74371-3-1-1 & 0.81 & 0.83 & 1.22 & 0.86 & 0.98 & 0.84 & 0.84 & 0.79 & 0.84 & 0.83 \\
\hline 3 & IR 80312-6-B-3-2-B & 1.53 & 0.76 & 0.09 & 0.99 & 0.96 & 0.70 & 0.88 & 1.00 & 0.83 & 0.86 \\
\hline 4 & IR 78875-131-B-1-4 & 0.46 & 1.13 & 0.97 & 0.97 & 0.93 & 0.96 & 0.83 & 0.88 & 0.86 & 0.89 \\
\hline 5 & IR 79906-B-5-3-3 & 1.20 & 0.87 & 0.24 & 1.04 & 0.94 & 0.69 & 0.77 & 0.87 & 0.73 & 0.77 \\
\hline 6 & IR 79906-B-192-2-1 & 0.80 & 0.85 & 0.50 & 1.28 & 0.94 & 0.87 & 0.87 & 0.94 & 0.77 & 0.87 \\
\hline 7 & IR 55419-04 & 0.76 & 0.69 & 1.15 & 0.92 & 0.93 & 0.80 & 0.82 & 0.75 & 0.77 & 0.79 \\
\hline 8 & CR 2624 & 0.71 & 0.75 & 0.95 & 0.75 & 0.83 & 1.00 & 1.00 & 0.97 & 1.00 & 1.00 \\
\hline 9 & IR 78878-53-2-2-4 & 0.57 & 0.94 & 1.04 & 0.85 & 0.89 & 0.97 & 0.90 & 0.90 & 0.92 & 0.93 \\
\hline 10 & Lalat & 1.75 & 1.14 & 1.73 & 1.56 & 1.65 & 0.80 & 0.99 & 0.90 & 0.86 & 0.89 \\
\hline 11 & Annada & 0.52 & 0.75 & 1.16 & 0.37 & 0.71 & 0.88 & 0.84 & 0.79 & 0.92 & 0.86 \\
\hline 12 & Anjali & 1.10 & 1.12 & 0.66 & 0.96 & 1.04 & 0.85 & 0.87 & 0.97 & 0.90 & 0.91 \\
\hline Mean & & 0.91 & 0.90 & 0.88 & 0.95 & 0.98 & 0.86 & 0.87 & 0.89 & 0.86 & 0.87 \\
\hline
\end{tabular}

Table.2 Estimates of stability and adaptability parameters of grain yield $\left(\mathrm{t} \mathrm{ha}^{-1}\right)$ for twelve rice genotypes at four farmers filed

\begin{tabular}{|c|c|c|c|c|c|}
\hline S. $\mathbf{N}$. & Genotypes & $\begin{array}{l}\text { Mean Grain } \\
\text { Yield }\left(\mathrm{t} \mathrm{ha}^{-1}\right)\end{array}$ & $\begin{array}{c}\text { Regression Coefficient } \\
\left(\mathbf{b}_{\mathbf{i}}\right)\end{array}$ & $\begin{array}{c}\text { Deviation from } \\
\text { Regression }\left(\mathbf{S}^{2}{ }_{\text {di }}\right)\end{array}$ & $\begin{array}{c}\text { Coefficient of } \\
\text { Determination }\left(\mathbf{R}_{\mathbf{i}}{ }^{2}\right) \\
\end{array}$ \\
\hline 1 & IR 78875-53-2-2-2 & 3.76 & 0.51 & 0.01 & 60 \\
\hline 2 & IR 74371-3-1-1 & 3.49 & 0.40 & 0.01 & 81 \\
\hline 3 & IR 80312-6-B-3-2-B & 3.61 & 1.78 & 0.13 & 61 \\
\hline 4 & IR 78875-131-B-1-4 & 3.71 & 1.47 & 0.09 & 25 \\
\hline 5 & IR 79906-B-5-3-3 & 3.13 & 0.51 & 0.01 & 47 \\
\hline 6 & IR 79906-B-192-2-1 & 3.63 & 0.89 & 0.03 & 62 \\
\hline 7 & IR 55419-04 & 3.22 & 1.01 & 0.04 & 21 \\
\hline 8 & CR 2624 & 4.18 & 0.99 & 0.00 & 88 \\
\hline 9 & IR 78878-53-2-2-4 & 3.89 & 0.77 & 0.02 & 58 \\
\hline 10 & Lalat & 3.64 & 1.59 & 0.09 & 20 \\
\hline 11 & Annada & 3.51 & 0.90 & 0.03 & 52 \\
\hline 12 & Anjali & 3.34 & 0.88 & 0.03 & 8 \\
\hline
\end{tabular}




\section{Stability analysis}

Mean grain yield varied among environments and ranged from $3.02 \mathrm{t} \mathrm{ha}^{-1}$ for $\mathrm{F}_{4}$ to $4.32 \mathrm{t}$ ha1 for $F_{3}$ (Table 1). The presence of genotype $x$ location interactions indicates that particular genotypes tended to rank differently in grain yields at different locations. The broad sense heritability $\left(h_{b}\right)$ was 54.0 for grain yield, indicating that grain yield is a complex character and is greatly affected by different farmer's field. An analysis of variance for stability revealed significant differences for grain yield among genotypes and farmer's field. This reveals not only the amount of variability that existed among environments but also the presence of genetic variability among the genotypes. The mean square for $\mathrm{G}$ $\mathrm{x} E$ interaction was significant for grain yield. Significant $F$ values were found for GE interaction (linear) for grain yield, indicating differences among the regression coefficients. The mean grain yield of the 13 rice genotypes ranged from $3.13 \mathrm{t} \mathrm{ha}^{-1}$ to $4.18 \mathrm{tha}^{-1}$ and the highest grain yield was obtained from genotypes IR 78875-131-B-1-4, IR 78875-532-2-2, IR 78878-53-2-2-4 and CR 2624 (Table 2). It was emphasized that both linear (bi) and non-linear $\left(\mathrm{S}^{2} \mathrm{di}\right)$ components of GE interactions are necessary for judging the stability of a genotype (Eberhart and Russell, 1966). The regression coefficients (bi values) ranging from 0.40 to 1.78 . This large variation in regression coefficients indicates different responses of genotypes to environmental changes.

Genotypes with high mean yield, a regression coefficient equal to the unity $(\mathrm{bi}=1)$ and small deviations from regression $\left(\mathrm{S}^{2} \mathrm{di}=0\right)$ are considered stable (Finlay and Wilkinson, 1963; Eberhart and Russell, 1966). Accordingly, genotypes CR 2624 was the most stable for grain yield because their regression coefficients were almost equal to unity and they had lower deviations from regression with high $\mathrm{R}_{\mathrm{i}}$ (88\%) values (Pinthus, 1973), conforming their stability. In contrast, genotype IR 78875-131-B-1-4 for grain yield had regression coefficients greater than one, and so was regarded as sensitive to environmental changes.

Genotypes IR 78875-53-2-2-2 and IR 7887853-2-2-4 had less than unity $(\mathrm{bi}<1.0)$ regression coefficients, but they had high grain yields. These genotypes are, therefore, insensitive to environmental changes and have adapted to the poor environments. Furthermore, IR 78875-131-B-1-4 had regression coefficients significantly greater than unity for grain yields over mean grain yield. Therefore, this genotype is sensitive to environmental changes and can be recommended for cultivation under favourable conditions. The genotype $x$ environment interaction for grain yield was studied in rice (Kishore et al., 2002, Subudhi et al., 2008 and Subudhi et al., 2012).

\section{Participatory varietal selection}

During maturity stage, farmers were taken around the trials and participated in varietal selection. Farmers were asked to rank three best varieties as first, second and third as per their perceived criteria. Thirty per cent farmers have ranked CR 2624 as first followed by IR 78878-53-2-2-4 (23\%) and Annada (17\%). The other varieties which were given first preference each by 7 per cent farmers were IR 55419-04 and Lalat. The second rank was given mainly to four varieties. CR 2624, Annada, IR 78878-53-22-4 and IR 55419-04 were ranked second by 30 per cent, 20 per cent, 20 per cent and 13 per cent, respectively. The third rank was given mainly to three varieties like CR 2624 (25\%) followed by Annada (17\%) and IR 74371-3-1-1 (13\%). On the whole, CR 2624 was preferred by most of the farmers followed by IR 78878-53-2-2-4, IR 74371-3-1-1 and 
IR-55419-04. The reasons subscribed by the farmers for preferring the varieties were i) panicle length and weight, ii) grain type, iii) number of tillers per hill and iv) more straw.

Yield penalty and stability of aerobic rice have to be considered before promoting in tropics. The investigation at CRRI, Cuttack on aerobic rice indicated that substantial yield can be obtained with significant amount of water saving by 30-40 per cent. Yield is the most important breeding objective, direct selection for yield under aerobic is effective hence, the genotypes which yielded $4.2 \mathrm{t} \mathrm{ha}^{-1}$ under both water regimes, needs some morpho-physiological adjustments for yield contributing traits to develop new aerobic rice varieties with minimum yield gap. The cultivar superiority based on quantitative data (breeders' criteria) and qualitative preference scores (farmers' criteria) often showed synergies, however, there were differences as well. This indicates farmers' ability to choose superior cultivars based on qualitative observation compared to tedious quantitative data recording in the on-station testing.

\section{References}

Ahmad R, Quadir S, Ahmad N and Shah KH (2003).Yield Potential and Stability of Nine Wheat Varieties under Water Stress Conditions. International Journal of Agriculture and Biology 5 (1): 7-9.

Barker R, Dawe D, Tuong TP, Bhuiyan SI and Guerra LC (1999). The outlook of water resources in the year 2020: Challenges for research on water management in rice production. In: Assessment and Orientation towards the $21^{\text {st }}$ century. Proceedings of $19^{\text {th }}$ session of the International Rice Commission, Cario, Egypt. 7-9 September, 1998. pp. 96-109. FAO, Rome (Italy).

Borell A, Garside A and Shu FK (1997). Improving efficiency of water for irrigated rice in a semi-arid tropical environment. Field Crops Research 52: 231-248.

Bouman BAM, Wang Hua Qi, Yang Xiao Guang, Zhao Jun Fang and Wang Chang Gui, 2002. Aerobic rice (Han Dao): a new way of growing rice in water-short areas. In: Proceedings of the 12th International Soil Conservation Organization Conference, 26-31 May 2002, Beijing, China. Tsinghua University Press, p. 175-181.

Eberhart SA and Russell WA (1966). Stability parameters for comparing varieties. Crop Science 6: 36-40.

Finlay KW and Wilkinson GN (1963). The analysis of adaptation in a plantbreeding programme. Australian Journal of Agricultural Research 14: 742-754.

Fischer RA and Maurer R, 1978. Drought resistance in spring wheat cultivars. I. Grain yield responses. Australian Journal of Agricultural Research 29: 897-912.

Gomez KA and Gomez AA (1984). Statistical Procedures for Agricultural Research ( $2^{\text {nd }}$ Edition). John Wiley \& Sons. Inc. $680 \mathrm{p}$.

IRRI, 2009. CropStat 7.2 for Windows. Crop Research Informatics Laboratory, International Rice Research Institute, Los Banos, Philippines.

Kishore K, Singh NK, Niraj Kumar and Thakur R (2002). Genotype X Environment interaction and stability analysis for grain yield and some associated traits in boro rice. Oryza 39: 12-14.

Li YH (2001). Research and practice of water-saving irrigation for rice in China. In: Barker, R. Li, Y. and Tuong T. P., Water-saving irrigation for rice. Proceedings of an International Workshop, 23-25 Mar 2001, Wuhan, China. Colombo (Sri Lanka): International Water Management 
Institute. p. 135-144.

Lin Shan, Dittert K and Sattelmacher B (2002). The ground cover rice production system (GCRPS) - a successful new approach to save water and increase nitrogen fertilizer efficiency? In: Water-Wise Rice Production. (Eds. Bouman, Hengsdijk, Hardy, Bindraban, Tuong, Lafitte and Ladha). Los Baños (Philippines): IRRI.

Pantuwan G, Fukai S, Cooper M, Rajatasereekul, S, and O'Toole JC (2002). Yield response of rice (Oryza sativa L.) genotypes to different types of drought under rainfed lowlands Part 1 Grain yield and yield components. Field Crops Research 73: 153-168.

Pinthus MJ (1973). Estimates of genotypic value: a proposed method. Euphytica 22: 345-351.

Singh RK and Chaudhury BD (1985). Biometrical Methods in Quantitative Genetic Analysis. Kalyani Publishers, New Delhi, India.
Stoop W, Uphoff N and Kassam A (2002). A review of agricultural research issues raised by the system of rice intensification (SRI) from Madagascar: opportunities for improving farming systems for resource-poor farmers. Agricultural Systems 71: 249-274.

Subudhi HN, Bose LK, Singh ON and Rao GJN (2012). Genotype x Environment interaction for grain yield and its component traits in irrigated Rice. The Madras Agricultural Journal 99 (4-6): 178-180.

Subudhi HN, Meher J and Bose LK (2008). Stability analysis for grain yield in some rice varieties. Environment and Ecology 26: 2199-2201.

Tabbal DF, Bouman BAM, Bhuiyan SI, Sibayan EB and Sattar MA (2002). Onfarm strategies for reducing water input in irrigated rice; case studies in the Philippines. Agricultural Water Management 56(2): 93-112.

\section{How to cite this article:}

Mall, A.K., S.K. Pradhan and Singh, O.N. 2017. Development of Potential Aerobic Rice Cultivar through Participatory Varietal Selection Employing Aerobic Response Index. Int.J.Curr.Microbiol.App.Sci. 6(8): 3577-3583. doi: https://doi.org/10.20546/ijcmas.2017.608.429 